\title{
Rare Case of Prolapsing Vaginal Cyst
}

\author{
Shalini Mahana Valecha, Neha Shah, Manisha Gandhewar, Prajakta Shende
}

\begin{abstract}
Müllerian cysts typically are $<2 \mathrm{~cm}$ in size and asymptomatic. Our patient presented with big mass coming out per vaginum and intermittent vaginal discharge. A provisional diagnosis of first degree uterovaginal descent with cystorectocele with small right lateral vaginal wall cyst was made. The patient was posted for vaginal hysterectomy with anteroposterior colporrhaphy with excision of the cyst. What we thought was a routine vaginal hysterectomy for prolapse allotting another few minutes for a small cyst removal, turned out to be a complicated procedure, requiring additional time and expertize. Not all patients presenting with mass coming out per vaginum, necessarily, are a case of prolapse. One should not minimize the importance of vaginal wall cysts, irrespective of their size. A detailed evaluation, using MRI scan is indicated, prior to proceeding with their removal.
\end{abstract}

Keywords: Müllerian, Uterovaginal descent, Vaginal discharge, Cyst excision, Magnetic resonance imaging.

How to cite this article: Valecha SM, Shah N, Gandhewar M, Shende P. Rare Case of P rolapsing Vaginal Cyst. J South Asian Feder Obst G ynae 2013;5(1):40-41.

\section{Source of support $\mathrm{Nil}$}

Conflict of interest: None declared

\section{INTRODUCTION}

Cysts of the vaginal wall are relatively uncommon and often an incidental finding. ${ }^{1} \mathrm{~V}$ aginal cysts can be histologically classified as epithelial, inclusion, M üllerian, mesonephric and urothelial in addition to other rare types. ${ }^{2}$ M üllerian cysts typically are $<2 \mathrm{~cm}^{3}$ in size and asymptomatic. If at all they are symptomatic they present as a visible or palpable mass, dyspareunia, voiding problem, vaginal discharge and pain. ${ }^{4}$ M üllerian duct cysts are remnants of embryologic paramesonephric ducts. ${ }^{3}$

\section{CASE REPORT}

A 42-year-old lady para 2 came to the gynecological service of Employees State Insurance Postgraduate Institute of M edical Sciences and Research and Model Hospital, M umbai, India complaining of a big mass coming out per vaginum since 9 years. As per history the mass was reducible. She also complained of excessive vaginal discharge intermittently. Patient had no bowel, bladder or menstrual complaints. On examination, her vitals were stable and systemic examination was within normal limits. On per speculum, first degree uterovaginal descent with minimal cystorectocele was noted. A $3 \times 3 \mathrm{~cm}$ cystic swelling under the mucosa of the right lateral vaginal wall protruding out of the introitus was present. There was no visible punctum. On bimanual examination, uterus was retroverted, bulky, freely mobile with both fornices clear. Cyst was tense, nontender. A provisional diagnosis of first degree uterovaginal descent with cystorectocele with small right lateral vaginal wall cyst was made. The patient was posted for vaginal hysterectomy with anteroposterior colporrhaphy with excision of the cyst.

\section{Operative Procedure and Intraoperative Findings}

Vaginal hysterectomy with anteroposterior colporrhaphy was completed under spinal anesthesia. Incision was given over the tense cyst wall. M ucinous material of approximately $50 \mathrm{cc}$ was drained and sent for culture sensitivity. Dissection of the cyst wall from adjacent vaginal wall was started. We found that the cyst was a unilocular blind sac. A finger was inserted in the cavity to determine its extent. To our utter surprise, the cyst was extending deeply along the right lateral vaginal wall nearly up to the right fornix. Only with extensive sharp dissection ${ }^{5}$ could the cyst wall be separated from the vaginal wall and the cyst was removed in toto with difficulty. A large cavity, whose upper extent could not be visualized, remained. Since, there was no active hemorrhage within this enormous dead space, no sutures were taken. An absorbable gelatine sponge was kept within the cavity and the vaginal mucosa at the introitus closed with interrupted delayed absorbable sutures. $V$ agina was packed tightly for 24 hours. Postoperative course was uneventful. Histopathological examination showed Müllerian cyst of vaginal wall with mucin secreting, tall columnar epithelium of endocervical type. ${ }^{1,5}$ Culture sensitivity of the cyst contents showed pus cells ++ , Streptococcus + , Enterococcus + both sensitive to amoxycillin + clavulanic acid. Postoperatively patient was given course of this antibiotic for 7 days. Patient followed up in OPD after 6 weeks. Vaginal mucosa healed well and patient had no complaints.

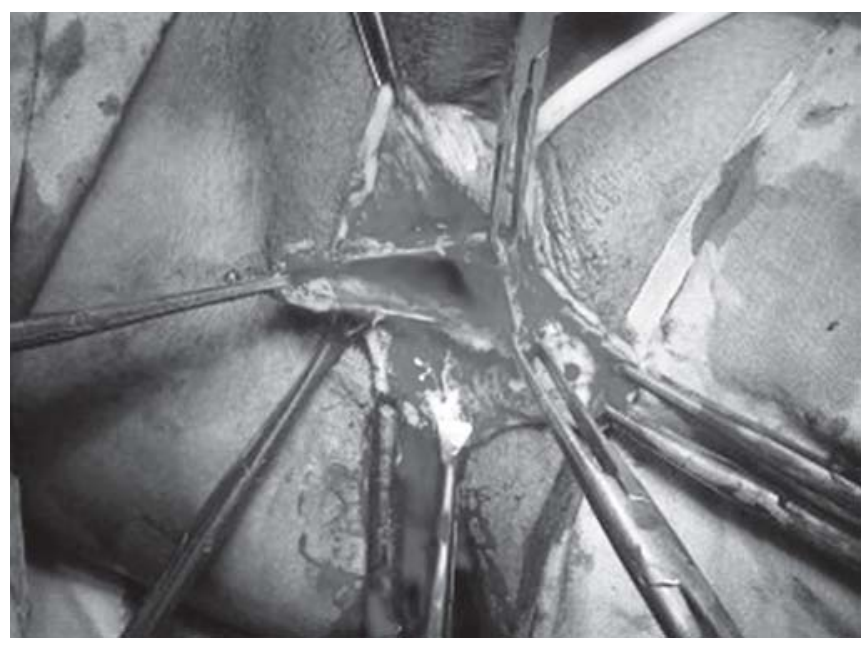

Fig. 1: Vaginal cyst dissected before resection 
Rare Case of Prolapsing Vaginal Cyst

\section{DISCUSSION}

M üllerian cysts typically present in the child-bearing age, 5,6 unusually, this patient presented in the perimenopausal age. L arge cysts are al most al ways symptomatic and patient presents with complaints of dispareunia, difficulty in micturition or defecation, vaginal discharge and pain. ${ }^{4}$ O ur patient presented with big mass coming out per vaginum and intermittent vaginal discharge. Preoperatively, we were misled by the small size of the cyst and attributed her symptoms only to the uterovaginal descent with minimal cystorectocele. Retrospectively, we concluded that the huge Müllerian cyst was probably filling up, repeatedly with mucinous material discharging intermittently, with the patient interpreting it as leukorrhea. The main complaint of the patient, then, was really the cyst coming out per vaginum and with its penchant for filling and discharging on its own. What we thought was a routine vaginal hysterectomy for prolapse allotting another few minutes for a small cyst removal, turned out to be a complicated procedure, requiring additional time and expertize. Had we correctly eval uated the cyst preoperatively by M RI we would have been better prepared to remove this enormous cyst. Perhaps, the uterus may have then be left in situ after discussing the same with the patient. Ultrasound though an acceptable modality, M RI, with its better resolution for pelvic and perineal pathology is a superior diagnostic tool for all cysts along the vaginal walls irrespective of their size..$^{7-9}$ One must not minimize the importance of a vaginal wall cyst, even if they clinically appear small and inconsequential. Thorough radiographic evaluation is advised before proceeding for removal. ${ }^{10}$

\section{CONCLUSION}

Not all patients presenting with mass coming out per vaginum, necessarily, are a case of prolapse. ${ }^{3,9}$ One should not minimize the importance of vaginal wall cysts, irrespective of their size. A detailed evaluation, using M RI scan is indicated, prior to proceeding with their removal.

\section{REFERENCES}

1. K ondi-Pafiti A, Grapsa D, Papakonstantinou K, K airi-V assilatou E, Xasiakos D. Vaginal cysts: A common pathologic entity revisited. Pathology Laboratory. Clin Exp Obstet Gynecol 2008;35(1):41-44.

2. Sahnidt WN. Pathology of the vagina-V aginal cysts. In: Fox $\mathrm{H}$, W ella M (Eds). Haines and Taylor Obstetrical and Gynecological
Pathology (5th ed). New Y ork: Churchill Livingstone 2003; $1: 180$.

3. K resowik J, K ennedy CM, Wing S, Galask RP, R oy J, Lucille A (Eds). Prolapsing vaginal cyst: A case report. J Reprod Med 2007 Sep;52(9):852-54.

4. Rashmi, Suneja A, A garwal N, Guleria K, Y adav P. Vaginal mullerian cyst presenting as enterocele. J Obstet Gynecol India. January/February 2009;59(1):74-76.

5. J ayaprakash S, Lakshmidevi M , Sampath K umar G. A rare case of posterior vaginal wall cyst. BM J Case Reports 2011.

6. Junaid TA, Thomas SM. Cysts of the vulva and vagina: A comparative study. Int J Gynaecol Obstet 1981;19:239-43.

7. Hagspiel KD. Giant gartner duct cyst: Magnetic resonance imaging findings. A bdom Imaging 1995;20:566-68.

8. Cil A P, Basar M M , Kara SA, A tasoy P. Diagnosis and management of vaginal mullerian cyst in a virgin patient. IntU rogynecol J Pelvic Floor Dysfunct. 2008 M ay;19(5):735-37. Epub 2007 N ov 16.

9. M ontella JM . Vaginal mullerian cyst presenting as a cystocele. Obstet Gynecol 2005 M ay;105(5 Pt 2):1182-84.

10. Eilber K S, Raz S. B enign cystic lesions of the vagina: A literature review. J U rol 2003 Sep;170(3):717-22.

\section{ABOUT THE AUTHORS}

\section{Shalini Mahana Valecha}

Professor, D epartment of O bstetrics and Gynecology, Employees State InsurancePostgraduate Institute of M edical Sciences and R esearch and M odel Hospital, M umbai, M aharashtra, India

CorrespondenceAddres 606, Panch L eela, Near SM Shetty School Powai, M umbai, M aharashtra, India, e-mail: shalini.mahana@ gmail.com

\section{Neha Shah}

Senior Resident, Department of Obstetrics and Gynecology Empl oyees State Insurance Postgraduate Institute of M edical Sciences and Research and M odel Hospital, M umbai, M aharashtra, India

\section{Manisha Gandhewar}

Associate Professor, Department of Obstetrics and Gynecology E mpl oyees State Insurance Postgraduate Institute of M edical Sciences and Research and M odel Hospital, M umbai, M aharashtra, India

\section{Prajakta Shende}

Assistant Professor, Department of Obstetrics and Gynecology Empl oyees State Insurance Postgraduate Institute of M edical Sciences and Research and M odel Hospital, M umbai, M aharashtra, India 